\title{
DEFINING THE STUDENT BURNOUT CONSTRUCT: A STRUCTURAL ANALYSIS FROM THREE BURNOUT INVENTORIES ${ }^{1}$
}

\author{
JOÃO MAROCO
}

ISPA-IU Lisboa, Portugal

\author{
JULIANA ALVARES DUARTE BONINI CAMPOS
}

FOAR-UNESP São Paulo, Brazil

Summary.-College student burnout has been assessed mainly with the Maslach Burnout Inventory (MBI). However, the construct's definition and measurement with MBI has drawn several criticisms and new inventories have been suggested for the evaluation of the syndrome. A redefinition of the construct of student burnout is proposed by means of a structural equation model, reflecting burnout as a second order factor defined by factors from the MBI-Student Survey (MBI-SS); the Copenhagen Burnout Inventory-Student Survey (CBI-SS) and the Oldenburg Burnout Inventory-Student Survey (OLBI-SS). Standardized regression weights from Burnout to Exhaustion and Cynicism from the MBI-SS scale, Personal Burnout and Studies Related Burnout from the CBI, and Exhaustion and Disengagement from OLBI, show that these factors are strong manifestations of students' burnout. For college students, the burnout construct is best defined by two dimensions described as "physical and psychological exhaustion" and "cynicism and disengagement."

Burnout is defined as a response, drawn out in time, to chronic interpersonal stressors in the work place. It comprises three key dimensions: emotional exhaustion, depersonalization, and reduction of personal accomplishment (Schaufeli, Leiter, \& Maslach, 2009). Initially, burnout was considered a psychological syndrome specific to professionals performing human services or support tasks for other people (e.g., doctors, lawyers, psychologists, teachers, etc.). Research on the burnout syndrome has shown, however, that burnout is not exclusive to human services professionals; on the contrary, it can also be found in other professional activities (Leiter \& Schaufeli, 1996). The concept of burnout has also been applied to people involved in activities such as full-time motherhood (Pelsma, Roland, Tollefson, \& Wigington, 1989; Balogun, Helgemoe, Pellegrini, \& Hoeberlein, 1996) and undergraduate/graduate, full-time studies (McCarthy, Pretty, \& Catano, 1990; Koeske \& Koeske, 1991; Balogun, et al., 1996). Following the initial construct's definition by Christa Maslach and collaborators, student burnout is usually defined as a tri-factorial, psychological syndrome characterized by an exhaustion state due to coursework demand, a cynical and detached attitude towards the college degree, and a feeling of low efficacy and academic achievement (Schaufeli, Martínez, Pinto, Salanova, \& Bakker, 2002).

Burnout in full-time students has received more attention, since students' performance in academic and social contexts (McCarthy, et al., 1990;

${ }^{1}$ Address correspondence to João Maroco, Statistics \& Health and Psychology Research Unit, ISPA-IU, Rua Jardim do Tabaco 34, Lisbon, 1149-041 Portugal or e-mail (jpmaroco@ispa.pt). 
Schaufeli, et al., 2002), school dropout rates (Koeske \& Koeske, 1991; Dyrbye, Thomas, Massie, Power, Eacker, Harper, et al., 2010), and physical and psychological distress (Koeske \& Koeske, 1991; Watson, Deary, Thompson, \& Li, 2008) including suicidal ideation (Dyrbye, et al., 2008), have been hypothesized to be strongly correlated with burnout. College students are particularly prone to burnout since they experience multiple socio-economic, relational, and socio-professional outcome concerns during their studies (Schaufeli, et al., 2002; Maroco \& Tecedeiro, 2009). Despite the relevance of academic performance in the social and academic integration of students and its apparent relation with burnout as a precursor for more serious psychological, physical, and academic performance unbalances (McCarthy, et al., 1990; Koeske \& Koeske, 1991; Dyrbye, et al., 2008; Dyrbye, Thomas, Power, Durning, Moutier, Massie, et al., 2010), the evaluation and diagnosis of burnout in college students is hampered by the limitations of burnout measurement scales, as well as theoretical indeterminacies on the burnout construct, both in students (Maroco, Tecedeiro, Martins, \& Meireles, 2008) and in other professionals (Demerouti, Bakker, Vardakou, \& Kantas, 2003; Cox, Tisserand, \& Taris, 2005; Halbesleben \& Demerouti, 2005; Kristensen, Borritz, Villadsen, \& Christensen, 2005; Schaufeli \& Salanova, 2007).

Most of the published research concerning burnout in students has used the Maslach Burnout InventoryI-General Survey (MBI-GS; McCarthy, et al., 1990; Balogun, et al., 1996) or the MBI-Student Survey (MBI-SS; Schaufeli, et al., 2002; Schaufeli \& Taris, 2005; Hu \& Schaufeli, 2009). However, the MBI (in its different forms) has drawn several criticisms. Firstly, it does not have a global burnout score, making it difficult to characterize one's burnout status (Demerouti, et al., 2003; Kristensen, et al., 2005). Secondly, although the tri-factorial structure has been confirmed in multiple sample types and professionals (Worley, Vassar, Wheeler, \& Barnes, 2008; Schaufeli, et al., 2009; Makikangas, Hatinen, Kinnunen, \& Pekkonen, 2011) including students (Schaufeli, et al., 2002; Hu \& Schaufeli, 2009), some of its psychometric characteristics have been challenged. Demerouti, et al. (2003) have drawn attention to the fact that the items for Depersonalization and Exhaustion scales are negatively worded, while the items for Professional Accomplishment are positively worded, affecting the MBI's scores' distribution and the conceptualization of the burnout construct. Furthermore, some MBI items show cultural bias, and the different versions of this instrument have brought some confusion regarding the three core burnout dimensions (Kristensen, et al., 2005).

Furthermore, the validity of the personal accomplishment factor as a key dimension of burnout is being challenged. An early study by Schutte, Toppinen, Kalimo, \& Schaufeli (2000) showed that, within the MBI, Personal Accomplishment develops independently from Exhaustion and De- 
personalization, suggesting that personal accomplishment may not be part of the total burnout construct. Demerouti, Bakker, Nachreiner, and Schaufeli (2001) also suggested that burnout is best defined by only two correlated dimensions: Exhaustion and Disengagement from work, which are largely invariant across occupational groups (Demerouti, et al., 2001; Demerouti, et al., 2003; Halbesleben \& Demerouti, 2005). Furthermore, they add the notion that emotional exhaustion and depersonalization constitute a syndrome which is loosely related to personal accomplishment. Kristensen, et al. (2005) even go a step further when defending that (reduced) personal accomplishment is more of a consequence than a burnout dimension (see also Sonnentag, 2005). Several confounding factors, like different target populations, countries, age groups, and social and cultural backgrounds, may explain the observed inconsistencies regarding the factorial structure and interpretation of MBI. For example, Kristensen, et al. (2005) found that Danish respondents reacted negatively to several items on the personal accomplishment scale because they represented ideas that were "too" American. Although these criticisms have been refuted (Schaufeli \& Taris, 2005; Schaufeli, et al., 2009), the absence of a global burnout score is still an unanswered limitation. Indeed, as Kristensen, et al. (2005) point out, the MBI tri-factor structure that does not add to a single estimate of burnout, results in one concept but three poorly correlated measures. Schaufeli and Taris (2005) also pointed out that the Dutch Association of Occupational Physicians recommended towards a global score on the MBI-GS. According to the Dutch association, this global burnout score should be used as a tool for diagnosing work-related mental problems. Quite recently, Wheeler, Vassar, Worley, and Barnes (2011) suggested that the emotional exhaustion subscale of the MBI may be used as a single global burnout factor in applied research settings to categorize individuals along a burnout continuum.

Drawing on the different criticisms to the MBI, Demerouti, et al. (2003) proposed and validated the two-factor Oldenburg Burnout Inventory (OLBI), while Kristensen, et al. (2005) developed a new three-factor burnout inventory named the Copenhagen Burnout Inventory (CBI). The authors suggest the use of these new inventories as valid and reliable alternatives to the MBI, and have published data supporting the validity and reliability of the new inventories in different professions (Demerouti, et al., 2003; Halbesleben \& Demerouti, 2005; Kristensen, et al., 2005; Yeh, Cheng, Chen, Hu, \& Kristensen, 2007). However, they still do not define a global burnout score.

Student burnout has been mainly assessed using the Maslach Burnout Inventory-Student Survey (MBI-SS) as proposed by Schaufeli, et al. (2002). Its three-factor conceptualization has been confirmed in multiple 
samples from different countries and study areas (Schaufeli, et al., 2002; Carlotto, Nakamura, \& Câmara, 2006; Maroco, et al., 2008; Watson, et al., 2008; Hu \& Schaufeli, 2009; Maroco \& Tecedeiro, 2009; Dyrbye, et al., 2010). However, the criticisms made to the general MBI tri-factor conceptualization and item formulation, recommends toward a concurrent evaluation of student burnout using different burnout inventories. To evaluate the different scales that measure burnout and their relation with the construct itself is a key research topic, especially if one considers that the MBI was, and still is, the 'gold standard' measure of this syndrome.

Quite recently, the OLBI and CBI were adapted for Portuguese-speaking college students, after the permission from the scales' authors was secured (Campos, Zucoloto, Bonafé, Jordani, \& Maroco, 2011). These studies have demonstrated that data gathered with the Portuguese versions of the OLBI and CBI show construct related validity reliability, as well as criterion related validity when compared to two of the three factors from the MBI-SS (Campos, et al., 2011). Although the CBI was originally composed of three factors, in the study by Campos, et al. (2011) a fourth factor (Teacher-related burnout) was added. That fourth factor reflects burnout caused by the interaction with teachers during classes, homework assignments and correction, and tests (see Campos, et al., 2011 for details). OLBI and CBI have been proposed as two of the main alternatives to MBI (see e.g. Cox, et al., 2005). Therefore, its adaptation to college students constitutes a supported alternative to the MBI-SS.

In the present study, burnout in student samples was measured using the MBI-SS and forms of the OLBI and CBI adapted for students. Objectives are (1) to identify the total number of factors contributing to student burnout, and (2) gather empirical support for the definition of burnout as a second order hierarchical factor.

\section{METHOD}

\section{Participants}

University students (989 women, $M$ age $=22.5$ yr., $S D=5.0$; 581 men ( $M$ age $=24.9$ yr., $S D=6.8)$ from Brazil $(n=958)$ and Portugal $(n=612)$ participated voluntarily in this study. The mean age of the participants was 23.4 yr. $(S D=5.8)$. Participants attended both private $(63 \%)$ and public $(37 \%)$ colleges, majoring in Biological sciences $(7 \%)$, Exact Sciences $(21 \%)$, Social and Human sciences (41\%), and Health and Medical Sciences (31\%). Most participants were living with their families (63\%) who also paid for tuition and fees $(65 \%)$. Most students $(63 \%)$ were in the middle of their 5-year degree.

\section{Measures}

Socio-demographic characteristics of the participants were assessed 
through a custom-built questionnaire. Burnout dimensions were assessed with the Malasch Burnout Inventory-Student Survey (MBI-SS), the Oldenburg Burnout Inventory adapted for students (OLBI-SS), and the Copenhagen Burnout Inventory adapted for students (CBI-SS), previously adapted transculturally to Portuguese-speaking students from both Portugal and Brazil, after securing the authorization from the inventories' authors (see below and Campos, et al., 2011).

The Maslach Burnout Inventory-SS comprises 15 ordinal items, scored on a 7-point, Likert-type scale (anchors of 0: Never and 6: Always). MBISS defines three factors, Exhaustion, Cynicism, and Efficacy (see Schaufeli, et al., 2002, for a detailed description of MBI-SS). The Oldenburg Burnout Inventory (OLBI; Kristensen, et al., 2005) comprises 16 ordinal items (anchors of 1: Completely disagree and 4: Completely agree) with positive and negative formulations. These 16 items define two factors, Exhaustion and Disengagement (see Halbesleben \& Demerouti, 2005, for a detailed description of the English version of the OLBI). The Copenhagen Burnout Inventory (CBI) comprises 18 ordinal items (anchors of 1: Never and 5: Always) which define three factors, Personal Burnout, Work-related Burnout, and Client-related Burnout (see Kristensen, et al., 2005, for a detailed description; see also Table 1 for the complete description of the adapted inventories' items). The good psychometric qualities of the data gathered from the Portuguese versions of these instruments have been reported for several different Portuguese-speaking college students' samples (Carlotto, et al., 2006; Maroco \& Tecedeiro, 2009; Campos, et al., 2011) and were also evaluated within the present study.

\section{Procedure}

A web site was designed for the sociodemographic questionnaire and the burnout inventories in their Portuguese version. Participants were invited to participate voluntarily, being assured that no personal or other information, which could be used to identify the participants, was required. Factorial invariance between paper and pencil versus internet formats was previously demonstrated in a pilot study (see Campos, et al., 2011). The questionnaires were available online for seven months to be filledout (May-November 2009). Each web page had a survey so that the respondent could view all items simultaneously. Non-responses were not allowed and participants could return to verify and / or correct the answer to each survey prior to its submission.

\section{Psychometric Evaluation}

Items' distributions. - Items' distributions were evaluated by the skewness and kurtosis of their frequency distributions. Items with absolute values of skewness lower than 3 and kurtosis lower than 7 did not deviate 
enough from the normal distribution to recommend against it in the subsequent factorial analysis (see Kline, 2004) .

Construct-related validity. - The factor structures proposed for each of the three burnout inventories used in this study were evaluated by confirmatory factorial analysis (CFA) with maximum likelihood estimation in $2 / 3$ of the original sample, randomly assigned to a test sample. Goodness of fit of the proposed structures to the correlational structure of the data was evaluated with $\chi^{2} / d f$, CFI, GFI, RMSEA and the $90 \%$ confidence interval for RMSEA. Good fit was assumed for $\chi^{2} / d f$ around 2, CFI and GFI greater than .9 and RMSEA lower than .05 with the upper limit of the $90 \%$ confidence interval lower than.08 (see, e.g., Bollen, 1989; Byrne, 2001; Kline, 2004). Items with factor loadings lower than 0.4 , or with modification indices for model fit improvement greater than $11(p<.001)$, were removed to improve the goodness of fit (Maroco, 2010). The factorial invariance of the factor structures was then evaluated by a multigroup CFA analysis, comparing the factor structures in the $2 / 3$ test sample versus $1 / 3$ validation sample. Differences of chi-squared statistics from the equally constrained factor weights and structural covariance models, and free parameters models were than probed for statistical significance. CFA and multigroup analysis were performed with SPSS-AMOS (v. 18, SPSS, Inc. Chicago, IL).

Convergent validity.-Items' convergence into the proposed factors was evaluated with the factor's average variance extracted (AVE) and composite reliability (CR), as described by Fornell and Larcker (1981). AVE greater than .50 and $C R$ greater than .70 were indicative of convergent validity (Hair, Anderson, Tatham, \& Black, 1998; Maroco, 2010).

Discriminant validity. - The factors' discriminant validity was assessed by comparing the AVE by each factor with the squared Pearson correlation between factors. As proposed by Fornell and Larcker (1981), evidence for discriminant validity was obtained when the squared correlation between factors was larger than the AVE for each factor.

\section{Reliability}

The lower limit of the true factor's reliability was estimated using Cronbach's alpha $(\alpha)$, and the CR was estimated as defined by Fornell and Larcker (1981).

\section{Burnout as a Second-order Factor}

Despite the fact that a burnout factor structure with three separate but highly interrelated factors has been supported consistently in the psychometric literature (see Worley, et al., 2008; Kim \& Ji, 2009; Makikangas, et al., 2011), we think that student burnout could be defined as a secondorder hierarchical factor. Thus, it was hypothesized that burnout can be 
reflected in the first-order factors present in the three burnout inventories (MBI-SS, OLBI-SS and CBI-SS). The conceptualization of burnout as a second-order factor reflected in Exhaustion, Cynicism, Efficacy for the MBI-SS, Exhaustion and Disengagement for the OLBI-SS, and Personal, Work-related, Student-related, and Teacher-related burnout for the CBISS, is in line with the theoretical construction of burnout as a multifactorial structure and its most recent criticisms (see Cox, et al., 2005; Halbesleben \& Demerouti, 2005; Schaufeli, et al., 2009). Burnout, as a second-order hierarchical factor, also would yield a global burnout score, as pointed out by Kristensen, et al. (2005). A two-step model-fitting strategy was followed (Jöreskog \& Sörbom, 1993). In the first step, items that cross-loaded on more than one scale were deleted and goodness of fit for the measurement model was confirmed; in the second step, the beta weights for the trajectories, from the second-order burnout construct to its first-order factors, were probed for statistical significance with $z$ tests for large samples.

\section{RESULTS}

\section{Psychometric Properties}

Item distributions. - Table 1 gives descriptive statistics for items in MBI-SS, CBI-SS, and OLBI-SS. None of the items showed skewness and kurtosis absolute values indicative of severe violations of normality preventing further use in factorial analysis.

\section{Construct-related Validity}

Overall, the original factor structures for the three inventories were maintained with acceptable fit in the present sample, as evaluated by the confirmatory factor analysis (see Table 2). The average variance extracted $(A V E)$ was greater than .50 for all the factors in CBI-SS and MBI-SS, but not for OLBI-SS. In contrast, composite reliability was greater than .7 for all factors. With the exception of the OLBI-SS factors, all others had an AVE greater than the squared Pearson correlation between factors. Construct-related validity can, thus, be accepted for CBI-SS and MBI-SS but not for OLBI-SS.

External validity of these conclusions was supported by a multigroup CFA on the independent validation sample, where factorial invariance was observed for MBI-SS $\left[\chi^{2}(12)=21.64, p=.04\right.$ for factor weights; $\chi^{2}(6)=8.52, p=.20$ for structural covariances], CBI-SS $\left[\chi^{2}(19)=20.77, p=.35\right.$ for factor weights; $\chi^{2}(10)=9.02, p=.53$ for structural covariances] and OLB I-SS $\left[\chi^{2}(12)=15.67, p=.21\right.$ for factor weights; $\chi^{2}(3)=3.31, p=.35$ for structural covariances).

\section{Reliability}

Reliability for all of the burnout factors, as estimated by Cronbach's $\alpha$, was greater than .70, being larger than .80 for MBI-SS and CBI-SS. Sim- 
TABLE 1

Descriptive Statistics for the Burnout Inventories' Items $(N=1,570)$

\begin{tabular}{|c|c|c|c|c|c|c|}
\hline Inventory/Item & $M$ & $M d n$ & Mode & $S D$ & Kurtosis & Skew \\
\hline \multicolumn{7}{|l|}{ MBI-SS } \\
\hline 1. Feel emotionally drained & 2.78 & 3 & 2 & 1.57 & -0.66 & 0.29 \\
\hline 2. Feel used up at the end of a day & 3.80 & 4 & 3 & 1.93 & -0.89 & -0.13 \\
\hline 3. Feel tired getting up in the morning & 2.64 & 2 & 2 & 1.71 & -0.86 & 0.30 \\
\hline 4. Studying or attending a class is strain & 2.21 & 2 & 1 & 1.67 & -0.43 & 0.64 \\
\hline 5. Burned out from studies & 2.42 & 2 & 2 & 1.66 & -0.59 & 0.49 \\
\hline 6. Less interested in studies & 1.28 & 1 & 0 & 1.61 & 0.98 & 1.34 \\
\hline 7. Less enthusiastic about studies & 1.43 & 1 & 0 & 1.54 & 0.83 & 1.19 \\
\hline 8. More cynical about usefulness of studies. & 1.41 & 1 & 0 & 1.63 & 0.47 & 1.15 \\
\hline 9. Doubt the significance of studies & 1.78 & 1 & 0 & 1.81 & -0.15 & 0.93 \\
\hline 10. Effectively solve problems in studies & 3.98 & 4 & 5 & 1.57 & -0.54 & -0.58 \\
\hline 11. Make effective contribution to classes & 3.70 & 4 & 5 & 1.65 & -0.82 & -0.38 \\
\hline 12. I am a good student & 3.94 & 4 & 5 & 1.50 & -0.35 & -0.57 \\
\hline 13.Feel stimulated achieving study goals & 5.00 & 5 & 6 & 1.33 & 2.39 & -1.58 \\
\hline 14. Learned many interesting things & 4.66 & 5 & 5 & 1.31 & 1.18 & -1.11 \\
\hline 15. Confident of effectiveness during class & 3.95 & 4 & 5 & 1.37 & -0.32 & -0.46 \\
\hline \multicolumn{7}{|l|}{ CBI-SS } \\
\hline 1. Often feel tired & 3.26 & 3 & 3 & 0.84 & -0.39 & 0.13 \\
\hline 2. Often physically exhausted & 2.96 & 3 & 3 & 0.96 & -0.48 & 0.28 \\
\hline 3. Often emotionally exhausted & 2.94 & 3 & 3 & 0.99 & -0.51 & 0.19 \\
\hline 4. Often can't take it anymore & 2.48 & 2 & 2 & 1.09 & -0.43 & 0.52 \\
\hline 5. Often feel worn out & 2.68 & 3 & 2 & 1.00 & -0.31 & 0.42 \\
\hline 6. Often weak and susceptible to illness & 2.20 & 2 & 2 & 1.01 & 0.27 & 0.79 \\
\hline 7. Worn out at the end of day & 3.02 & 3 & 3 & 1.03 & -0.56 & 0.16 \\
\hline 8. Exhausted in the morning & 2.42 & 2 & 2 & 1.08 & -0.31 & 0.57 \\
\hline 9. Working hours are tiring & 2.50 & 2 & 2 & 0.96 & -0.14 & 0.45 \\
\hline 10. Enough energy for family, friends & 3.53 & 4 & 4 & 1.10 & -0.70 & -0.36 \\
\hline 11. Work emotionally exhausting & 2.63 & 3 & 2 & 1.01 & -0.25 & 0.38 \\
\hline 12. Work frustrating & 2.16 & 2 & 2 & 1.04 & 0.05 & 0.74 \\
\hline 13. Feel burnt out because of work & 2.33 & 2 & 2 & 1.03 & -0.17 & 0.58 \\
\hline 14. Hard to work with colleagues & 2.30 & 2 & 2 & 1.08 & -0.08 & 0.66 \\
\hline 15. Drains energy to work with colleagues & 2.24 & 2 & 2 & 1.05 & 0.02 & 0.71 \\
\hline 16. Frustrating to work with colleagues & 1.96 & 2 & 1 & 1.06 & 0.44 & 1.05 \\
\hline $\begin{array}{l}\text { 17. Give more than you get back from col- } \\
\text { leagues }\end{array}$ & 2.47 & 2 & 2 & 1.12 & -0.73 & 0.35 \\
\hline 18. Tired of working with colleagues & 1.96 & 2 & 1 & 1.08 & 0.37 & 1.03 \\
\hline $\begin{array}{l}\text { 19. Do you sometimes wonder how long you } \\
\text { will be able to continue working with col- } \\
\text { leagues? }\end{array}$ & 1.88 & 2 & 1 & 1.10 & 0.64 & 1.20 \\
\hline 20. Hard to work with teachers & 2.13 & 2 & 2 & 0.97 & 0.29 & 0.74 \\
\hline 21. Drains energy to work with teachers & 1.90 & 2 & 1 & 0.97 & 0.78 & 1.06 \\
\hline
\end{tabular}

Note.-Due to copyright restrictions, all items have been shortened and their format modified, to give only a feel for the item content. 
TABLE 1 (CONT'D)

Descriptive Statistics for the Burnout Inventories' Items $(N=1,570)$

\begin{tabular}{|c|c|c|c|c|c|c|}
\hline Inventory/Item & $M$ & $M d n$ & Mode & $S D$ & Kurtosis & Skew \\
\hline 22. Frustrating to work with teachers & 4.08 & 4 & 6 & 1.80 & -1.82 & -0.01 \\
\hline 23. Give more than you get back & 1.96 & 2 & 1 & 1.00 & 0.62 & 1.00 \\
\hline 24. Tired of working with teachers & 1.85 & 2 & 1 & 1.00 & 0.92 & 1.17 \\
\hline $\begin{array}{l}\text { 25. Wonder how long you can work with } \\
\text { teachers }\end{array}$ & 1.73 & 1 & 1 & 0.99 & 1.62 & 1.44 \\
\hline \multicolumn{7}{|l|}{ OLBI-SS } \\
\hline 1. New and interesting aspects in work & 1.98 & 2 & 2 & 0.67 & 0.27 & 0.36 \\
\hline 2. Feel tired before work & 3.04 & 3 & 3 & 0.80 & 0.10 & -0.64 \\
\hline 3. Talk about work negatively & 1.98 & 2 & 2 & 0.92 & 0.92 & 1.05 \\
\hline 4. Need more time to relax and feel better & 2.79 & 3 & 3 & 0.85 & -0.56 & -0.26 \\
\hline 5. Tolerate pressure well & 2.30 & 2 & 2 & 0.69 & 0.07 & 0.32 \\
\hline $\begin{array}{l}\text { 6. Lately, I tend to think less at work and } \\
\text { Do job mechanically }\end{array}$ & 2.23 & 2 & 2 & 0.78 & -0.28 & 0.27 \\
\hline 7. Work a challenge & 1.75 & 2 & 2 & 0.63 & 0.98 & 0.60 \\
\hline 8. Feel emotionally drained at wor & 2.54 & 2 & 2 & 0.79 & -0.46 & 0.12 \\
\hline 9. Can become disconnected & 2.10 & 2 & 2 & 0.81 & -0.31 & 0.40 \\
\hline 10. Enough energy for leisure & 2.36 & 2 & 2 & 0.83 & -0.48 & 0.21 \\
\hline 11. Feel sickened by work & 2.82 & 3 & 3 & 0.75 & 0.08 & -0.42 \\
\hline 12. Worn out after work & 2.64 & 3 & 3 & 0.75 & -0.34 & -0.06 \\
\hline 13. Only work I imagine doing & 2.52 & 3 & 3 & 1.01 & -1.07 & -0.15 \\
\hline 14. I can manage work well & 2.21 & 2 & 2 & 0.65 & 0.73 & 0.58 \\
\hline 15. I feel engaged & 2.29 & 2 & 2 & 0.72 & -0.18 & 0.16 \\
\hline 16. Work energizes & 2.65 & 3 & 3 & 0.72 & -0.13 & -0.22 \\
\hline
\end{tabular}

Note.-Due to copyright restrictions, all items have been shortened and their format modified, to give only a feel for the item content.

ilarly, CR was greater or equal to .78 for all the factors under study (see Table 2).

\section{Second-order Student Burnout Factor}

Following a two-step model-fit strategy, a measurement model, including the 9 factors from the three inventories, were fitted to the test sample. To improve fit and reduce loadings of item's errors on factor disturbances, as suggested by modification indices, Items 3 and 14 from the MBI-SS and Item 12 from the CBI-SS were removed. Also, item errors caused by the same factor were allowed to correlate. The measurement model showed an overall acceptable fit to the data $\left(\chi^{2} / d f=2.7 ; C F I=.94 ; G F I=.89 ; R M S E A=.04\right.$; $90 \% \mathrm{CI}=.040, .043)$ and overall moderate to high significant correlations between factors (see Table 2). In the second step, causal trajectories were added, from a second order burnout factor, to each of the 9 factors from the three inventories. The existence of a second order burnout factor is justified by the observed correlations between factors, lack of discriminant validity for some factors and theoretical considerations which justify a second- 
TABLE 2

Average Variance Extracted (AVE), Composite Reliability (CR), and SQuared Pearson Correlations $\left(r^{2}\right)$ Between Factors for Each of the Three Inventories (MBI-SS, CBI-SS, OLBI-SS) AND GOODNESS-OF-FIT INDICES OBSERVED IN THE CFA (Test and Validation Samples Combined; $N=1,570$ )

\begin{tabular}{|c|c|c|c|c|c|c|c|c|c|c|c|}
\hline \multirow[t]{2}{*}{ Inventory } & \multirow[t]{2}{*}{ AVE } & \multirow[t]{2}{*}{$\mathrm{CR}$} & \multirow[t]{2}{*}{$\alpha$} & \multicolumn{8}{|c|}{$r^{2}$} \\
\hline & & & & ExM & CY & $\mathrm{EF}$ & $\mathrm{ExO}$ & DIS & PB & SRB & CRB \\
\hline \multicolumn{12}{|c|}{ MBI-SS $\left(\chi^{2} / d f=7.86 ; C F I=.92 ; G F I=.91 ; R M S E A=.08,90 \% C I=.078, .089\right)$} \\
\hline Exhaustion (ExM) & .61 & .88 & .88 & & & & & & & & \\
\hline Cynicism (CY) & .64 & .88 & .87 & .32 & & & & & & & \\
\hline Efficacy (EF) & .44 & .82 & .82 & .02 & .07 & & & & & & \\
\hline \multicolumn{12}{|c|}{ OLBI-SS $\left(\chi^{2} / d f=5.42 ; \mathrm{CFI}=.90 ; \mathrm{GFI}=.94 ; \mathrm{RMSEA}=.07 ; 90 \% C I=.061, .073\right)$} \\
\hline Exhaustion (ExO) & .34 & .78 & .77 & .48 & .21 & .07 & & & & & \\
\hline Disengagement (DIS) & .34 & .78 & .73 & .21 & .41 & .14 & .27 & & & & \\
\hline \multicolumn{12}{|c|}{ CBI-SS $\left(\chi^{2} / d f=5.95 ; \mathrm{CFI}=.93 ; \mathrm{GFI}=.89 ; \mathrm{RMSEA}=.07 ; 90 \% C I=.067, .074\right)$} \\
\hline Personal burnout (PB) & .61 & .90 & .90 & .46 & .20 & .03 & .47 & .15 & & & \\
\hline $\begin{array}{l}\text { Studies-related burnout } \\
\text { (SRB) }\end{array}$ & .55 & .88 & .88 & .51 & .30 & .06 & .46 & .26 & .57 & & \\
\hline $\begin{array}{l}\text { Colleagues-related } \\
\text { burnout (CRB) }\end{array}$ & .63 & .91 & .91 & .07 & .06 & .00 & .06 & .02 & .12 & .10 & \\
\hline $\begin{array}{l}\text { Teachers-related burnout } \\
\text { (TRB) }\end{array}$ & .73 & .93 & .93 & .19 & .19 & .02 & .15 & .14 & .16 & .26 & .18 \\
\hline
\end{tabular}

order burnout factor (see Shirom \& Ezrachi, 2003; Maroco, et al., 2008; Qiao \& Schaufeli, 2011). Causal standardized regression (beta) weights between the second-order burnout factor and the nine factors from the three burnout inventories, are shown in Fig. 1. Although all beta weights are statistically significant $(p<.001)$, the second order burnout factor is best reflected in the CBI's Studies-related burnout $(\beta=.97 ; p<.001)$, OLBI's Exhaustion $(\beta=.88$; $p<.001)$, MBI's Exhaustion $(\beta=.86 ; p<.001)$, and CBI's Personal burnout $(\beta=.86, p<.001)$, explaining more than $74 \%$ of these factors' variance. Cynicism $(\beta=.69 ; p<.001)$ from MBI-SS, Disengagement $(\beta=.72 ; p<.001)$ from OLBI-SS, and CBI's teachers-related burnout $(\beta=.55 ; p<.001)$ were moderately affected by burnout, which explains between $30 \%$ and $45 \%$ of the variances of these factors. Low effect of burnout, although statistically significant, was observed in the CBI's colleagues-related burnout $(\beta=.39 ; p<.001)$ and MBI's efficacy $(\beta=-.41 ; p<.001)$. The variance explained for these factors was less than $20 \%$.

Stability of the statistical findings was assessed by a multigroup structural model analysis, comparing the estimates in the $2 / 3$ test sample with those obtained in the $1 / 3$ validation sample. Chi-squared differences between the models, with equally constrained estimates and free estimates, revealed no statistically significant differences in either the measurement weights $\left[\chi^{2}(39)=40.47, p=.41\right]$ or in the structural weights $\left[\chi^{2}(9)=4.55, p=.87\right]$. 


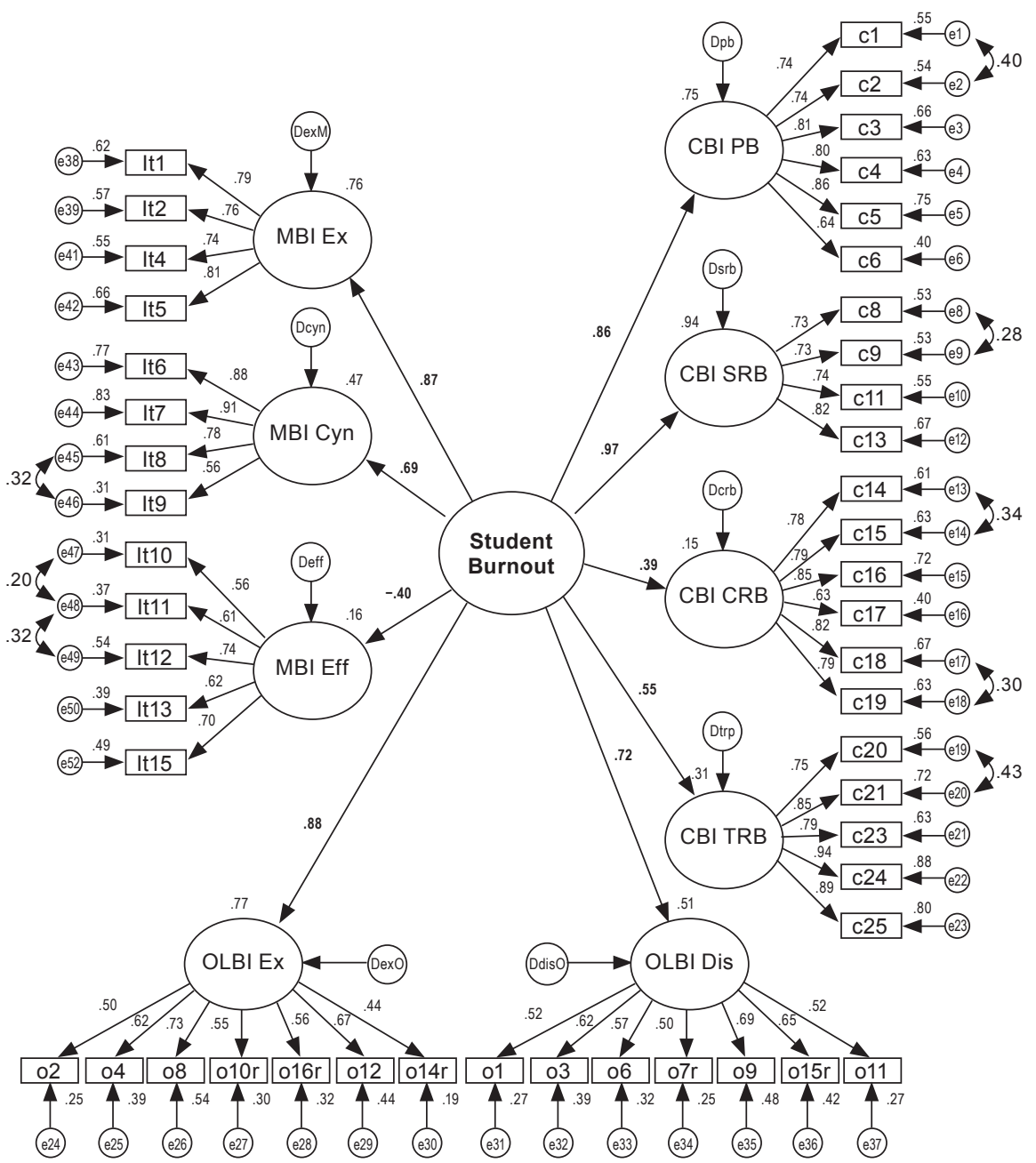

Fig. 1. Student burnout as second-order factor reflected in Exhaustion (MBI-Ex), Cynicism (MBI-Cyn) and Professional Efficacy (MBI-Eff) from MBI-SS, Exhaustion (OLBI-Ex) and Disengagement (OLBI-Dis) from OLBI-SS, and Personal Burnout (CBI-PB), Studies-related Burnout (CBI-SRB), Colleagues-related Burnout (CBI-CRB) and Teachers-related Burnout (CBI-TRB) from CBI-SS. All beta weights were statistically significant $(p<.001)$.

\section{DisCUSSION}

The relevance of burnout assessment in college students has been recognized for a long time (McCarthy, et al., 1990; Koeske \& Koeske, 1991; Balogun, et al., 1996; Schaufeli, et al., 2002; Schaufeli, et al., 2009). Early studies on the syndrome showed that burnout can influence the students' psycho- 
logical and physical well-being (McCarthy, et al., 1990; Koeske \& Koeske, 1991; Watson, et al., 2008) as well as their personal and academic achievements (Li, Song, \& Guo, 2009; Dyrbye, et al., 2010; Salanova, Schaufeli, Martinez, \& Breso, 2010). In extreme cases, it can lead to school dropout (Dyrbye, et al., 2010) or even suicide (Dyrbye, et al., 2008).

The dominant use of the MBI to assess burnout in different professions and countries has been recently challenged, and new burnout instruments have been proposed and tested (Demerouti, et al., 2001; Kristensen, et al., 2005; Qiao \& Schaufeli, 2011). Based on the three main inventories used to assess burnout in several service-related professions, an attempt was made to redefine the burnout construct specifically for students. As previously demonstrated with international student populations (Schaufeli, et al., 2002; Hu \& Schaufeli, 2009), the MBI-SS produced data that were reliable and showed construct-related validity. Good construct-related validity and reliability were also observed with the CBI-SS data. However, the two OLBI-SS factors did not show convergent or discriminant related validity, although factorial validity and reliability were present in both. Construct-related validity of data gathered from several professionals occupations, other than full-time students, have also been demonstrated for the CBI (Kristensen, et al., 2005; Yeh, et al., 2007) and OLBI (Demerouti, et al., 2003; Halbesleben \& Demerouti, 2005; Qiao \& Schaufeli, 2011). Data gathered in this study suggested that both CBI-SS and OLBI-SS, in addition to MBI-SS, can be used to assess burnout in college students.

The question remaining now is which inventory should one use to assess student burnout in college students? The answer requires a reevaluation of the construct definition as assessed by the different inventories used in its estimation. As pointed out by others (see Kristensen, et al., 2005), this methodology comprises a circular argument: burnout is assessed by its measurement instruments, thus burnout is what these instruments measure. However, (i) using different inventories to probe burnout as a second-order construct; and (ii) examining how burnout is reflected on each of the inventories' factors, one can assess how burnout is best defined by proposed instruments. This approach leads to a conceptual clarification for the burnout construct. It is possible that different burnout instruments, which share theoretical constructs, have strong correlations between burnout's key dimensions due to the fact that the different questionnaires include not different dimensions, but rather measure complementary aspects of the same dimension (for example, cynicism vs disengagement vs studies-related burnout in MBI, OLBI, and CBI, respectively). Indeed, the data gathered in this study showed that burnout is strongly reflected on the CBI-SS factors Studies and Personal Burnout, as well as the Exhaustion scales from the MBI-SS or the OLBI-SS. The sec- 
ond-order burnout construct explained more than $70 \%$ of these factors' variances. The Personal burnout factor in the CBI was created with the objective of assessing the fatigue or exhaustion of individuals, regardless of their occupational status, including young people, unemployed, pensioners, etc. According to Kristensen, et al. (2005), "Personal Burnout is the degree of physical and psychological fatigue and exhaustion experienced by the person," while work-related burnout was defined as "the degree of physical and psychological fatigue and exhaustion that is perceived by the person as related to his/her work." Since the students' main work-like activities are related to their college studies, we called this dimension "studies-related burnout," being that it intends to reflect the degree of physical and psychological fatigue related to the course-work. Thus, these two factors of the CBI-SS are essentially physical and psychological exhaustion, in accordance to the exhaustion factors from both MBI-SS (Schaufeli, et al., 2002) and OLBI (Demerouti, et al., 2001). Burnout is moderately reflected in MBI-SS' Cynicism and OLBI-SS' disengagement explaining almost $50 \%$ of these factors' variance. These results suggest that lack of belief in the outcomes of the course-work and college degree, as well as reduced interest in the school activities-which for students may be a behavioral attitude- are a moderate reflection of burnout.

Teacher and colleague-related burnout from CBI-SS and Efficacy from MBI-SS are the factors most poorly explained by the second-order burnout factor, which accounted for less than $30 \%$ of these factors' variance. The low prediction of Burnout on Efficacy may explain why, in a study on obstacles and facilitators that predict academic performance, Salanova, et al. (2010) did not find a significant mediating role of burnout (estimated from MBI-SS) on student's academic performance. As the results from these authors also suggest, Efficacy may not be a key dimension of burnout in college students. Following Kristensen's, et al. (2005) initial definition of work-related burnout, the teachers and colleagues-related burnout can be defined as the degree of physical and psychological fatigue and exhaustion that is perceived by the student as related to activities with fellow students and teachers. While teachers' demand for course-work may be a cause of stress and lead to a high workload, the relationship with teachers and fellow students are not an important manifestation of students' burnout. On the contrary, both teachers and fellow colleagues can help prevent and counteract the development of burnout through positive motivation and encouragement. Salmela-Aro, Kiuru, Pietikäinen, and Jokela (2008), in a study with Finnish students, observed that positive motivation received from teachers was negatively related to school-related burnout. Personal efficacy has been pointed out as a consequence of burnout, and a personality factor rather than a dimension of burnout (Shirom \& Ezrachi, 
2003). This may explain why burnout is poorly reflected in Efficacy in college students. Weak correlations of Efficacy with the other burnout dimensions of MBI have been observed in several studies. It is questionable if inefficacy, rather than efficacy, should be the third dimension of burnout, according to the Maslach's conceptualization of the construct (Schaufeli \& Salanova, 2007). Quite recently, Qiao and Schaufeli (2011) have reviewed some of the literature on the dimensionality of burnout and concluded from an empirical, theoretical, clinical, and psychometric evaluation of different burnout inventories, that burnout, in a sample of Chinese nurses, was best defined as a two-dimensional construct, leaving out professional efficacy. Our empirical model suggests that a global score for burnout in students can be calculated from the items in the MBI and OLBI Exhaustion scales, CBI Personal and Studies related burnout scales, and MBI Cynicism and OLBI Disengagement scales. Items in these scales are formulated in the same conceptual direction and their defining factors show strong and positive correlations supporting the calculation of a global score. This is not to say that these constructs require more items to improve their psychometric properties. Rather, selecting the best performing items from the different questionnaires and defining burnout as second-order factor can achieve a better definition of the construct from a strictly psychometric point-of-view. This suggestion requires further empirical validation, especially because we must acknowledge that non-probabilistic sampling may limit the generalization of the current conclusions.

\section{Concluding Remarks}

Results gathered in this study demonstrate that student burnout, as a second-order construct, is best reflected on two first-order factors that evaluate physical and psychological exhaustion, on the one hand, and cynicism and disengagement towards the course-work, on the other. These observations are in accordance with the proposals by Kristensen, et al. (2005) and Demerouti, et al. $(2001,2003)$, for whom the core reasons for burnout are fatigue and exhaustion, and with the observations made by Qiao and Schaufeli (2011), who found no empirical or theoretical support for a third burnout factor (Efficacy). The current results are in accord with the hypothesis of a two-factor dimensionality for burnout. Student burnout seems to be best defined as physical and psychological exhaustion associated with course-work activities and secondarily by cynicism and disengagement toward the course-work. A global score for burnout in college students can be estimated from items in these two dimensions.

\section{REFERENCES}

Balogun, J. A., Helgemoe, S., Pellegrini, E., \& Hoeberlein, T. (1996) Academic performance is not a viable determinant of physical therapy students' burnout. Perceptual and Motor Skills, 83, 21-22. 
BolLEN, K. A. (1989) Structural equations with latent variables. New York: Wiley.

BYrNe, B. M. (2001) Structural equation modelling with AMOS: basic concepts, aplications and programming. London: LEA.

Campos, J. A. D. B., Zucoloto, M. L., Bonafé, F. S. S., Jordani, P. C., \& Maroco, J. (2011) Reliability and validity of self reported burnout in college students: a cross randomized comparison of pencil-and-paper vs. online administration. Computers in Human Behavior, 27, 1875-1883.

Carlotto, M. S., Nakamura, A. P., \& CÂmara, S. G. (2006) Síndrome de burnout em estudantes universitários da área da saúde. Psico, 37(1), 57-62.

Cox, T., Tisserand, M., \& TARIS, T. (2005) The conceptualization and measurement of burnout: questions and directions. Work \& Stress, 19(3), 187-191. DOI: 10.1080 / 02678370500387109.

Demerouti, E., Bakker, A. B., Nachreiner, F., \& Schaufeli, W. B. (2001) The job demands-resources model of burnout. Journal of Applied Psychology, 86(3), 499-512. doi: $10.1037 / 0021-9010.86 .3 .499$.

Demerouti, E., Bakker, A. B., Vardakou, I., \& Kantas, A. (2003) The convergent validity of two burnout instruments. European Journal of Psychological Assessment, 19(1), 12-23. DOI: 10.1027 / / 1015-5759.19.1.12.

Dyrbye, L. N., Thomas, M. R., Massie, F. S., Power, D. V., Eacker, A., Harper, W., Durning, S., Moutier, C., Szydlo, D. W., Novotny, P. J., Sloan, J. A., \& Shanafelt, T. D. (2008) Burnout and suicidal ideation among U.S. medical students. Annals of Internal Medicine, 149(5), 334-341.

Dyrbye, L. N., Thomas, M. R., Power, D. V., Durning, S., Moutier, C., Massie, F. S., Harper, W., Eacker, A., Szydlo, D. W., Sloan, J. A., \& Shanafelt, T. D. (2010) Burnout and serious thoughts of dropping out of medical school: a multi-institutional study. Academic Medicine, 85(1), 94-102.

ForNelL, C., \& LARCKER, D. F. (1981) Evaluating structural equation models with unobservable variables and measurement error. Journal of Marketing Research, 18(1), 39-50.

Hair, J. F., Anderson, R. E., TATHAM, R. L., \& Black, W. C. (1998) Multivariate data analysis. (5th ed.) New York, London: Prentice Hall.

Halbesleben, J., \& Demerouti, E. (2005) The construct validity of an alternative measure of burnout: investigating the English translation of the Oldenburg Burnout Inventory. Work \& Stress, 19(3), 208-220. DOI: 10.1080/02678370500340728.

Hu, Q., \& Schaufeli, W. B. (2009) The factorial validity of the Maslach Burnout Inventory-Student Survey in China. Psychological Reports, 105(2), 394-408.

JÖRESKOG, K. G., \& SÖRBOM, D. (1993) LISREL 8: structural equation modeling with SIMPLIS command language. Chicago, IL.: Scientific Software International.

KIM, H., \& JI, J. (2009) Factor structure and longitudinal invariance of the Maslach Burnout Inventory. Research on Social Work Practice, 19, 325-339.

KLINE, R. B. (2004) Principles and practice of structural equation modeling. (2nd ed.) New York: Guilford.

Koeske, G. F., \& Koeske, R. D. (1991) Student "burnout" as a mediator of the stressoutcome relationship. Research in Higher Education, 32, 415-431.

Kristensen, T., Borritz, M., Villadsen, E., \& Christensen, K. (2005) The Copenhagen Burnout Inventory: a new tool for the assessment of burnout. Work \& Stress, 19(3), 192-207. DOI: $10.1080 / 02678370500297720$. 
Leiter, M. P., \& Schaufeli, W. B. (1996) Consistency of the burnout construct across occupations. Anxiety, Stress \& Coping: An International Journal, 9(3), 229-243. DOI: $10.1080 / 10615809608249404$.

LI, X-Y., SonG, X-X., \& GuO, C-T. (2009) A study on the relation between students' learning burnout and their social support, locus of control, adolescent stress in university. Chinese Journal of Clinical Psychology, 17(3), 287-289.

Makikangas, A., Hatinen, M., Kinnunen, U., \& PekKonen, M. (2011) Longitudinal factorial invariance of the Maslach Burnout Inventory-General Survey among employees with job-related psychological health problems. Stress and Health, 27, 347-352.

Maroco, J. (2010) Análise de Equações Estruturais: Fundamentos teóricos, Software e Aplicações. Pêro Pinheiro: Report Number.

Maroco, J., \& Tecedeiro, M. (2009) Inventario de Burnout de Maslach para estudantes portugueses. Psicologia, Saúde E Doenças, 10(2), 227-235.

Maroco, J., Tecedeiro, M., Martins, P., \& Meireles, A. (2008) O burnout como factor hierárquico de $2^{\mathrm{a}}$ ordem da Escala de Burnout de Maslach. Análise Psicológica, 4, 639-649.

McCarthy, M. E., Pretty, G. M., \& Catano, V. (1990) Psychological sense of community and student burnout. Journal of College Student Development, 31(3), 211-216.

Pelsma, D. M., Roland, B., Tollefson, N., \& Wigington, H. (1989) Parent burnout: validation of the Maslach Burnout Inventory with a sample of mothers. Measurement and Evaluation in Counseling and Development, 22(2), 81-87.

QIAO, H., \& SCHAUfeli, W. B. (2011) The convergent validity of four burnout measures in a Chinese sample: a confirmatory factor-analytic approach. Applied Psychology, 60(1), 87-111. DOI: 10.1111/j.1464-0597.2010.00428.x.

Salanova, M., Schaufeli, W., Martinez, I., \& Breso, E. (2010) How obstacles and facilitators predict academic performance: the mediating role of study burnout and engagement. Anxiety, Stress \& Coping, 23(1), 53-70. DOI: 10.1080/10615800802609965.

Salmela-Aro, K., Kiuru, N., Pietikäinen, M., \& Jokela, J. (2008) Does school matter? the role of school context in adolescents' school-related burnout. European Psychologist, 13(1), 12-23.

Schaufeli, W., Leiter, M. P., \& Maslach, C. (2009) Burnout: 35 years of research and practice. Career Development International, 14(3), 204-220. DOI: 10.1108/136 20430910966406

Schaufeli, W., Martínez, I. M., Pinto, A. M., Salanova, M., \& BakKer, A. B. (2002) Burnout and engagement in university students: a cross-national study. Journal of Cross-cultural Psychology, 33(5), 464-461.

Schaufeli, W., \& Salanova, M. (2007) Efficacy or inefficacy, that's the question: Burnout and work engagement, and their relationships with efficacy beliefs. Anxiety, Stress \& Coping, 20(2), 177-196. DOI: 10.1080/10615800701217878.

SCHAUfELI, W., \& TARIS, T. (2005) The conceptualization and measurement of burnout: Common ground and worlds apart. Work \& Stress, 19(3), 256-262. DOI: $10.1080 / 02678370500385913$.

Schutte, N., Toppinen, S., Kalimo, R., \& Schaufeli, W. (2000) The factorial validity of the Maslach Burnout Inventory/General Survey (MBI-GS) across occupational groups. Journal of Occupational and Organizational Psychology, 73, 53-66.

SHIROM, A., \& EzRACHI, Y. (2003) On the discriminant validity of burnout, depression, and anxiety: a re-examination of the burnout measure. Anxiety, Stress, and Coping, $16,83-99$. 
SONNENTAG, S. (2005) Burnout research: adding an off-work and day-level perspective. Work \& Stress, 19(3), 271-275. DOI: 10.1080/02678370500386473.

Watson, R., Deary, I., Thompson, D., \& LI, G. (2008) A study of stress and burnout in nursing students in Hong Kong: a questionnaire survey. International Journal of Nursing Studies, 45(10), 1534-1542. DOI: 10.1016/j.ijnurstu.2007.11.003.

Wheeler, D. L., Vassar, M., Worley, J. A., \& Barnes, L. B. (2011) A meta-analysis of coefficient alpha for the Maslach Burnout Inventory. Educational and Psychological Measurement, 7, 231-244.

Worley, J. A., Vassar, M., Wheeler, D. L., \& Barnes, L. L. B. (2008) Factor structure of scores from the Maslach Burnout Inventory: a review and meta-analysis of 45 exploratory and confirmatory factor-analytic studies. Educational and Psychological Measurement, 68(5), 797-823. DOI: 10.1177/0013164408315268.

Yeh, W-Y., Cheng, Y., Chen, C-J., Hu, P-Y., \& Kristensen, T. (2007) Psychometric properties of the Chinese Version of the Copenhagen Burnout Inventory among employees in two companies in Taiwan. International Journal of Behavioral Medicine, 14(3), 126-133.

Accepted October 11, 2012. 
Copyright of Psychological Reports is the property of Ammons Scientific, Ltd. and its content may not be copied or emailed to multiple sites or posted to a listserv without the copyright holder's express written permission. However, users may print, download, or email articles for individual use. 